\title{
Communication
}

\section{Spectroscopic Evidence of New Low-Dimensional Planar Carbon Allotropes Based on Biphenylene via On-Surface Ullmann Coupling}

\author{
Teng Zhang ${ }^{1, *(\mathbb{D}}$, Cesare Grazioli ${ }^{2} \mathbb{D}$, Huixia Yang ${ }^{1}$, Kaiyue Jiang ${ }^{3}$, Iulia Emilia Brumboiu ${ }^{4}{ }^{\mathbb{C}}$, Liangguang Jia ${ }^{1}$, \\ Liwei Liu ${ }^{1}$, Carla Puglia ${ }^{5}$, Xiaodong Zhuang ${ }^{3 \oplus}$ and Yeliang Wang ${ }^{1}$
}

1 School of Integrated Circuits and Electronics, MIIT Key Laboratory for Low-Dimensional Quantum Struc-ture and Devices, Beijing Institute of Technology (BIT), Beijing 100081, China; yanghuixia@bit.edu.cn (H.Y.); liangguang.jia@bit.edu.cn (L.J.); liwei.liu@bit.edu.cn (L.L.); yeliang.wang@bit.edu.cn (Y.W.)

2 IOM-CNR, Istituto Officina dei Materiali, Basovizza SS-14, Km 163.5, 34149 Trieste, Italy; grazioli@iom.cnr.it

3 The Meso-Entropy Matter Lab., The State Key Laboratory of Metal Matrix Composites, Shanghai Key Laboratory of Electrical Insulation and Thermal Ageing, School of Chemistry and Chemical Engineering, Frontiers Science Center for Transformative Molecules, Shanghai Jiao Tong University, Shanghai 200240, China; jiangkaiyue@sjtu.edu.cn (K.J.); zhuang@sjtu.edu.cn (X.Z.)

4 Department of Chemistry, Pohang University of Science and Technology (POSTECH), Pohang 37673, Korea; iubru@postech.ac.kr

5 Department of Physics and Astronomy, Uppsala University, P.O. Box 516, SE-751 20 Uppsala, Sweden; carla.puglia@physics.uu.se

Citation: Zhang, T.; Grazioli, C.; Yang, H.; Jiang, K.; Brumboiu, I.E.; Jia, L.; Liu, L.; Puglia, C.; Zhuang, X.; Wang, Y. Spectroscopic Evidence of New Low-Dimensional Planar Carbon Allotropes Based on Biphenylene via On-Surface Ullmann Coupling. Chemistry 2021, 3 , 1057-1062. https://doi.org/10.3390/ chemistry3030076

Academic Editors: Albano Cossaro and Edwin Charles Constable

Received: 23 August 2021

Accepted: 7 September 2021

Published: 13 September 2021

Publisher's Note: MDPI stays neutral with regard to jurisdictional claims in published maps and institutional affiliations.

Copyright: (c) 2021 by the authors. Licensee MDPI, Basel, Switzerland. This article is an open access article distributed under the terms and conditions of the Creative Commons Attribution (CC BY) license (https:// creativecommons.org/licenses/by/ $4.0 /)$.
* Correspondence: teng.zhang@bit.edu.cn

\begin{abstract}
The bottom-up synthesis and preliminary characterizations of a new biphenylene-based $2 \mathrm{D}$ framework are presented. This new low-dimensional carbon allotrope potentially completes the many hypothesized carbon networks based on biphenylene.
\end{abstract}

Keywords: 2D material; on-surface synthesis; biphenylene; synchrotron radiation

Biphenylene-based 2D carbon networks (Figure 1) are studied due to their promising mechanical, electronic and transport properties, for possible applications in photonics, optoelectronics, quantum information technology, energy storage and molecular filters [1-7]. The most promising procedure to obtain these networks is by means of an Ullmann-like reaction on a crystalline metal surface used as a catalyst. However, compared to the extensive theoretical modelling, limited experimental success was achieved to form large area frameworks. Just very recently, Qitang Fan et al. successfully synthesized, for the first time, a biphenylene network (BPN) [8], a nonbenzenoid carbon allotrope based on biphenylene (Figure 1c). The detailed morphology and electronic properties were characterized, showing that BPN has metallic electronic properties, clarifying the theoretical debate about the dielectric or metallic properties of BPN $[2,9,10]$.

Besides BPN, biphenylene carbon (also called graphenylene or BPC) is another form of a biphenylene-based 2D carbon network (Figure 1b), which is flat like graphene, formed by $\mathrm{sp}^{2}$ hybridization and with a tunable bandgap of about $1 \mathrm{eV}$, highlighting the possible applications in electronics $[1,4,5]$. The porous membrane structure of BPC also favors its role as a gas separator or anode material for lithium batteries and energy application [11,12]. Dissimilar to BPN, large-scale BPC has not been successfully synthesized yet.

Our present study shows very preliminary results of a new low-dimensional planar carbon allotrope based on biphenylene, using the molecular precursor $\mathrm{BPBr}_{2}$ (1,8-dibromobiphenylene, Figure 1d) on a $\mathrm{Cu}(111)$ substrate. In accordance with the findings of previous studies, the surface-confined Ullman-like reaction is not a singlestep process, but it includes at least one more intermediate step. The growth and the spectroscopic characterizations were performed at the ANCHOR endstation [13] of the 
(a)

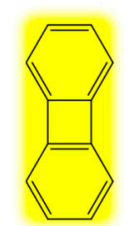

\section{Biphenylene}

(d)

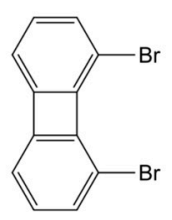

\section{1,8-dibromobiphenylene $\left(\mathrm{BPBr}_{2}\right)$}

ALOISA beamline at the Elettra Sincrotrone, Italy. The synthesis of $\mathrm{BPBr}_{2}$ and the details of the deposition are reported in the SI. The whole on-surface reaction was monitored in-situ by Photoelectron Spectroscopy (PES).

(b)

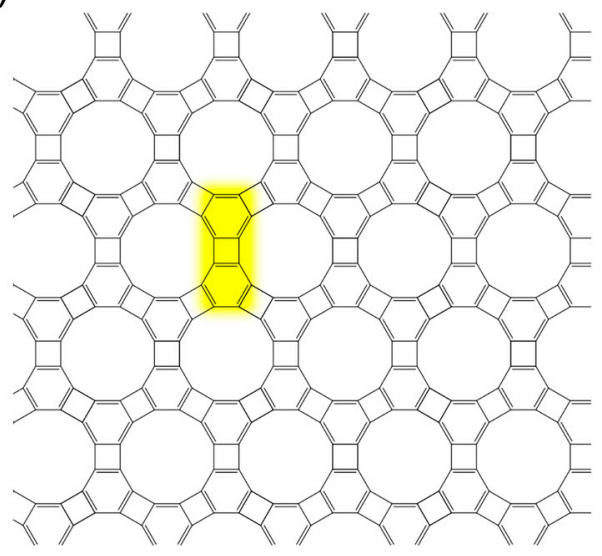

Biphenylene carbon (BPC) (c)

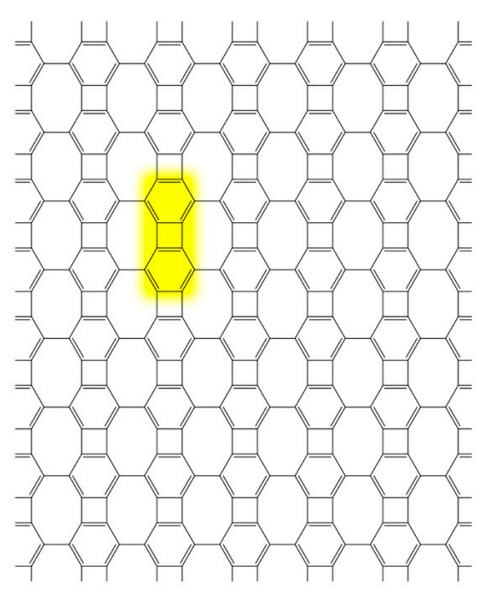

Biphenylene network (BPN)

Figure 1. (a) Structure of biphenylene. (b,c) Carbon allotropes based on biphenylene: biphenylene carbon (BPC) and biphenylene network (BPN), respectively. (d) The structure of the molecular precursor we used, $\mathrm{BPBr}_{2}$.

As shown in Figure 2a, we traced the synthesis process by annealing the $\mathrm{BPBr}_{2} / \mathrm{Cu}(111)$ system from RT to above $500{ }^{\circ} \mathrm{C}$, while simultaneously measuring the core-level PES maps of $\mathrm{C} 1 \mathrm{~s}, \mathrm{Cu} 3 \mathrm{p}$ and $\mathrm{Br} 3 \mathrm{~d}$. The binding energy was calibrated with the $\mathrm{Cu} 3 \mathrm{p}_{3 / 2}$ and $3 \mathrm{p}_{1 / 2}$ nominal values, 75.1 and $77.3 \mathrm{eV}$, respectively. We detected two main reaction steps. One happened in the $180-240{ }^{\circ} \mathrm{C}$ range with a significant chemical shift $(\Delta \mathrm{E}=0.66 \mathrm{eV})$ of the $\mathrm{C} 1$ s line towards a higher $\mathrm{BE}$, while the $\mathrm{Cu} 3 \mathrm{p}$ and $\mathrm{Br} 3 \mathrm{~d}$ lines did not change. This indicated the polymerization transition and the formation of $\mathrm{C}-\mathrm{C}$ covalent bonding (reaction 1 , yellow region) [14]. In the temperature region above $400{ }^{\circ} \mathrm{C}$, another reaction, i.e., the debromination process, started to occur (reaction 2, red region) where the $\mathrm{Br}$ atoms left the $\mathrm{Cu}(111)$ surface. The $\mathrm{Br} 3 \mathrm{~d}$ signal started to decrease at about $400{ }^{\circ} \mathrm{C}$ and no $\mathrm{Br} 3 \mathrm{~d}$ was observed above $480^{\circ} \mathrm{C}$. The debromination process also caused a modification of the $\mathrm{C} 1 \mathrm{~s}$ line profile and finished above $480^{\circ} \mathrm{C}$.

The high-resolution $\mathrm{C} 1 \mathrm{~s}, \mathrm{Cu} 3 \mathrm{p}$ and $\mathrm{Br} 3 \mathrm{~d} \mathrm{PE}$ spectra of $\mathrm{BPBr}_{2} / \mathrm{Cu}(111)$ of $\mathrm{RT}(1 \mathrm{~mL}$, as deposited), $250{ }^{\circ} \mathrm{C}$ (after reaction 1 ) and $515^{\circ} \mathrm{C}$ (after reaction 2 ) are presented in Figure $2 \mathrm{~b}, \mathrm{c}$. Note that for the as-deposited film at $\mathrm{RT}, \mathrm{C}-\mathrm{Br}$ dissociation already took place, i.e., the $\mathrm{Br}$ atoms detached from the molecule but still remained on the $\mathrm{Cu}(111)$ surface, as indicated by the stoichiometry of the C 1s PES and by the absence of the C-Br peak (expected at $\mathrm{BE}>286 \mathrm{eV}$ ) [14], which was also supported by the preliminary STM results (Figure S1). In fact, the $\mathrm{C}-\mathrm{Br}$ dissociation on $\mathrm{Cu}$ substrates usually happens below RT [15]. Both the $\mathrm{C}-\mathrm{C}(283.8 \mathrm{eV}$ in $\mathrm{BE})$ and $\mathrm{C}-\mathrm{Cu}$ bonds $(283 \mathrm{eV}$, at lower BE due to the more electropositive $\mathrm{Cu})$ contributed to the two peaks of the $\mathrm{C} 1 \mathrm{~s}$ PES, with a binding energy shift $(0.43 \mathrm{eV})$ that was compatible with previous results [16].

After annealing to $250{ }^{\circ} \mathrm{C}$, there was a shift of $0.66 \mathrm{eV}$ of the $\mathrm{C} 1 \mathrm{~s}$ line to a higher BE. This shift was associated with the polymerization transition in the $180-240{ }^{\circ} \mathrm{C}$ range, where the $\mathrm{C}-\mathrm{C}$ covalent coupling took place (see Figure $\mathrm{S} 2$ for preliminary STM result). Compared to $\mathrm{C}$ 1s PES, there was no evident change in the $\mathrm{Br} 3 \mathrm{~d}$ photoemission line at $250{ }^{\circ} \mathrm{C}$, which was another piece of proof that the $\mathrm{Br}$ was already detached from the molecule from $\mathrm{RT}$, but still remained on the $\mathrm{Cu}(111)$ surface [16]. Finally, at $515^{\circ} \mathrm{C}$, no $\mathrm{Br} 3 \mathrm{~d}$ signal was detected and the $\mathrm{C}-\mathrm{Br}$ shoulder was almost completely absent, indicating a polymeric network was 
formed (see Figure S3 for preliminary STM result). We note that the C 1s PE line profile here was similar to other 2D carbon allotropes such as graphene [17] or BPN [8].

(a)
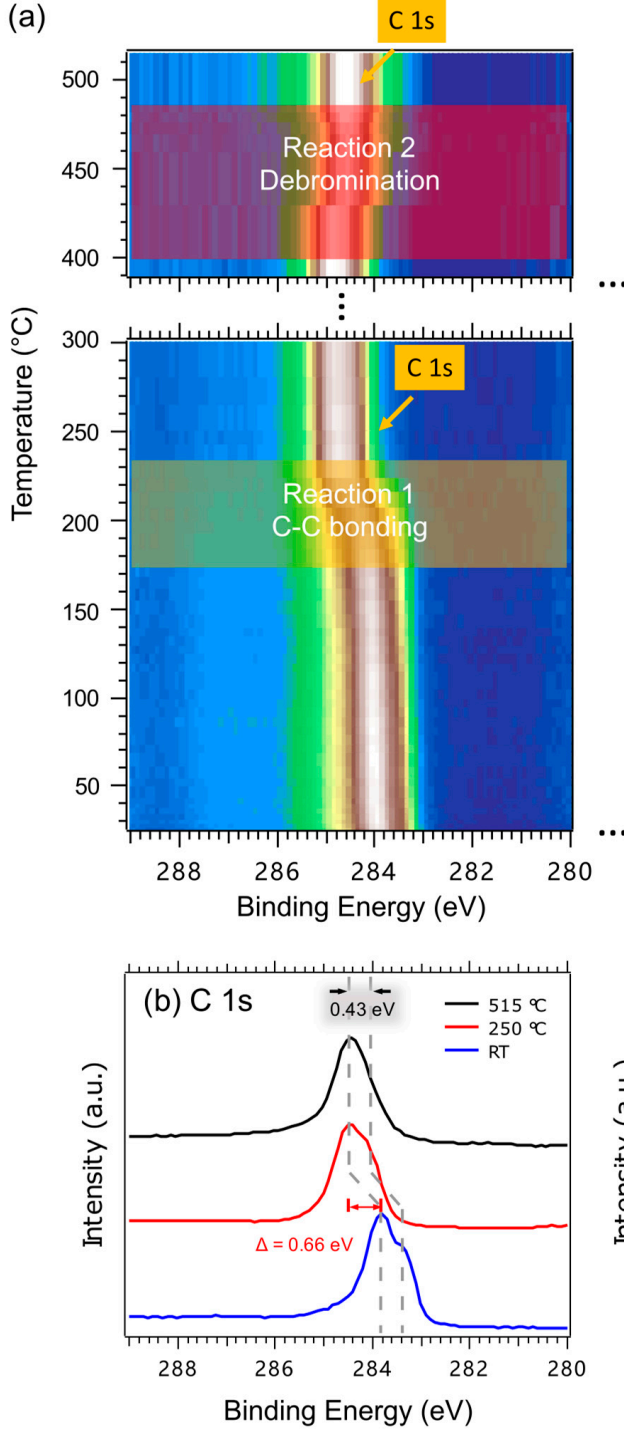
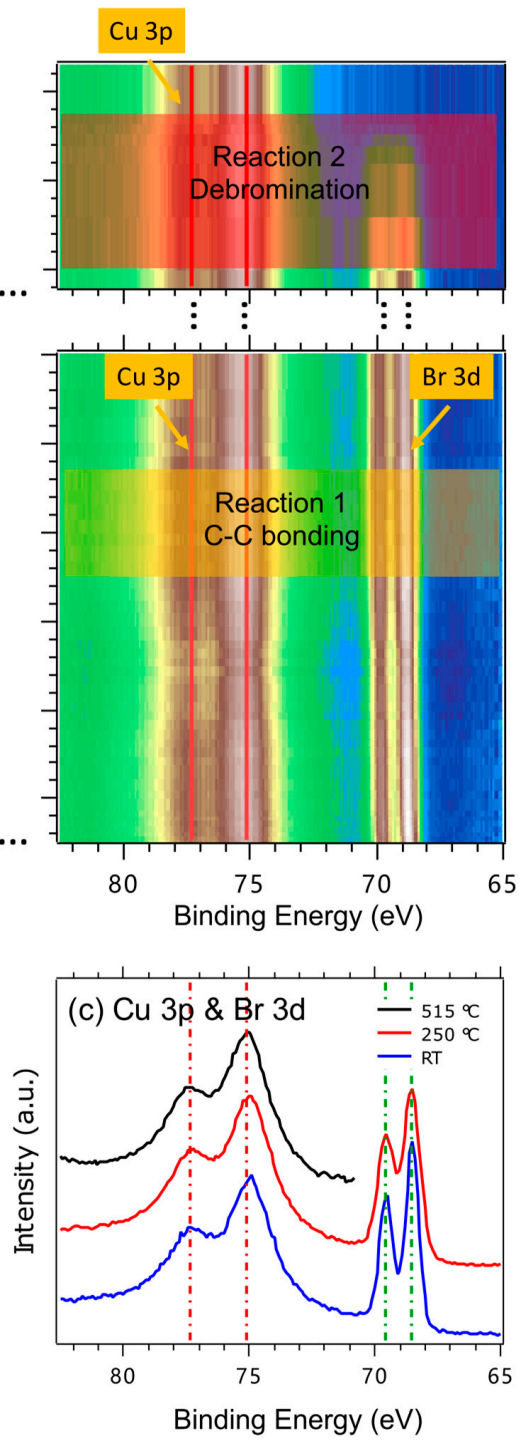

Figure 2. (a) Temperature-dependent $\mathrm{C} 1 \mathrm{~s}, \mathrm{Cu} 3 \mathrm{p}$ and $\mathrm{Br} 3 \mathrm{~d}$ PES during the annealing process measured with photon energy of $400 \mathrm{eV}$. Two main reactions, $\mathrm{C}-\mathrm{C}$ bonding $\left(180-240{ }^{\circ} \mathrm{C}\right)$ and debromination $\left(400-480^{\circ} \mathrm{C}\right)$, are labelled. (b,c) High resolution $\mathrm{C} 1 \mathrm{~s}, \mathrm{Cu} 3 \mathrm{p}$ and $\mathrm{Br} 3 \mathrm{~d}$ PES at room temperature (RT), $250{ }^{\circ} \mathrm{C}$ and $515{ }^{\circ} \mathrm{C}$.

The geometry of the system was investigated by means of the Near-Edge X-ray Absorption Fine Structure (NEXAFS) at the C K-edge. The C K-edge NEXAFS spectra of $\mathrm{BPBr}_{2} / \mathrm{Cu}(111)$ prepared at $\mathrm{RT}, 250^{\circ} \mathrm{C}$ and $515^{\circ} \mathrm{C}$ is shown in Figure 3. The polarizationdependent NEXAFS [18] showed that the $\pi^{*}$ resonance of the RT sample was strongly enhanced at normal incidence (NI) of the light, pointing to an almost standing adsorption geometry of the molecules $\left(68^{\circ} \pm 15^{\circ}\right)[19,20]$. At $250^{\circ} \mathrm{C}$, the polarization dependency was inverted and the $\pi^{*}$ resonance was, instead, enhanced at grazing incidence (GI). However, at NI, we could still see a small peak corresponding to the $\pi^{*}$ resonance, indicating that the phenyl rings were flatter on the surface, although not completely. At $515{ }^{\circ} \mathrm{C}$, we saw, instead, that the $\pi^{*}$ was only observed in the C K-edge NEXAFS spectrum taken at GI, while the $\sigma^{*}$ resonance was only visible at NI. Furthermore, these NEXAFS spectra resembled the results of prototypical 2D carbon networks such as graphene [17]. The strong polarization dependence of the NEXAFS spectra of the $515^{\circ} \mathrm{C}$ sample reflected the mostly 
planar adsorption geometry of the aromatic rings with respect to the surface. The planar adsorption geometry was a prerequisite to have a new low-dimensional planar carbon allotrope of $\mathrm{sp}^{2}$ hybridization based on biphenylene.

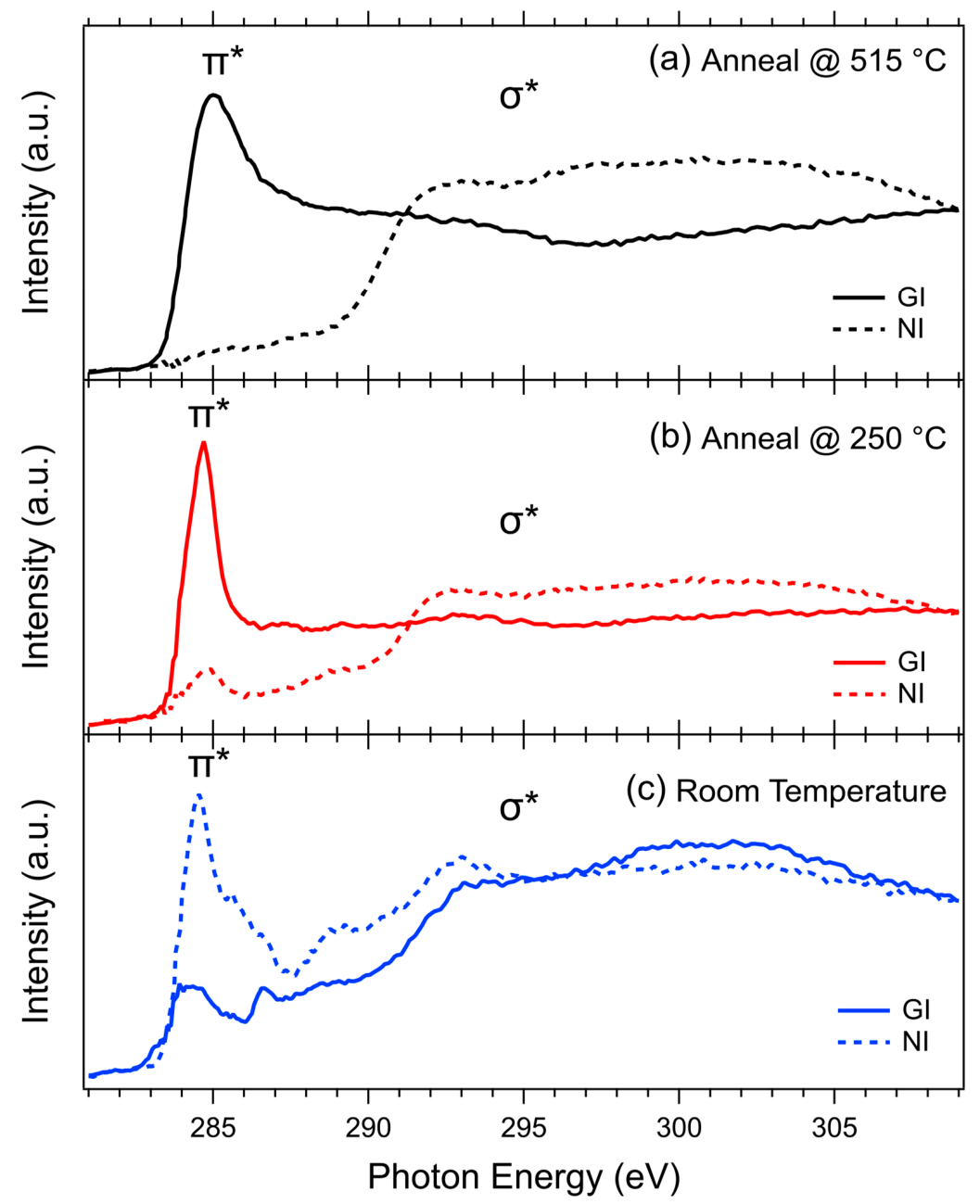

Figure 3. Polarization-dependent $\mathrm{C}$ K-edge NEXAFS spectra of $\mathrm{BPBr}_{2} / \mathrm{Cu}(111)$ after thermo treatment: (a) anneal at $515{ }^{\circ} \mathrm{C}$, (b) anneal at $250{ }^{\circ} \mathrm{C}$ and (c) as deposited (RT). The $\pi^{*}$ and $\sigma^{*}$ resonances were dependent on the grazing incident (GI) and normal incident (NI) polarizations, respectively, which is the so-called "linear dichroism of NEXAFS".

Figure 4a presents the Ultraviolet Photoelectron Spectroscopy (UPS) results of samples measured with a He II source taken at a normal emission, together with the corresponding Angle-Resolved Ultraviolet Photoelectron Spectroscopy (ARUPS) maps reported in Figure $4 \mathrm{~b}-\mathrm{d}$, as a function of the binding energy and the emission angles. Compared to the bare $\mathrm{Cu}(111)$ surface, the as-deposited $\mathrm{BPBr}_{2} / \mathrm{Cu}(111)$ presented two new features at about 2.2 and $4.2 \mathrm{eV}$ (indicated by the blue arrows). After annealing to $250^{\circ} \mathrm{C}$, the formation of $\mathrm{C}-\mathrm{C}$ covalent bonds resulted in a new feature at about $8 \mathrm{eV}$. Finally, annealing to $515^{\circ} \mathrm{Cleft}$ only the feature at $a b .8 \mathrm{eV}$ while the features at $a b .2 .2$ and $4.2 \mathrm{eV}$ disappeared. Therefore, the feature at $a b .8 \mathrm{eV}$ was attributed to the covalently bonded low-dimensional planar carbon allotropes. In fact, the $250^{\circ} \mathrm{C}$ annealed film already presented a band dispersion with the emission angle (Figure $4 \mathrm{c}$ ) and it became more evident after annealing to $515^{\circ} \mathrm{C}$, as marked by the black curve in the map (Figure 4b). According to band theory, only homogeneous structures can have such a band dispersion. It means that, after annealing $\mathrm{BPBr}_{2} / \mathrm{Cu}(111)$ at $515^{\circ} \mathrm{C}$, we obtained a highly ordered low-dimensional planar carbon allotrope. The presence of these delocalized electronic states in the film also indicated that the system may have had good internal charge transport properties, making it suitable to 
be exploited as an electrode material in electronic devices [21]. Moreover, the high (above $500{ }^{\circ} \mathrm{C}$ ) annealing temperature meant that this new low-dimensional film also exhibited a very good thermal stability.

(a)

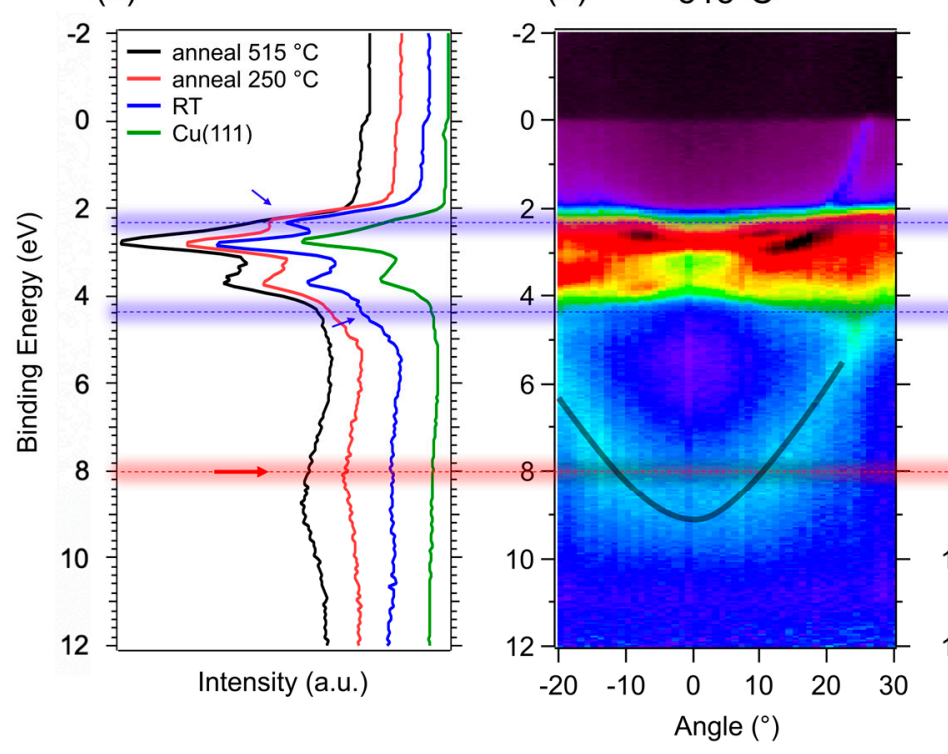

(c) $250^{\circ} \mathrm{C}$

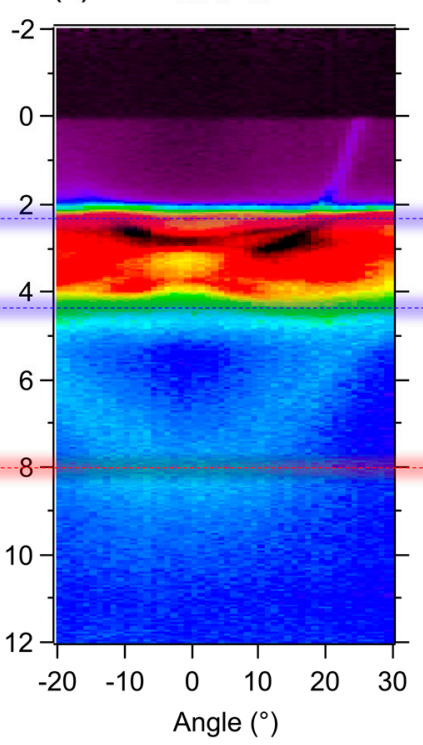

(d)

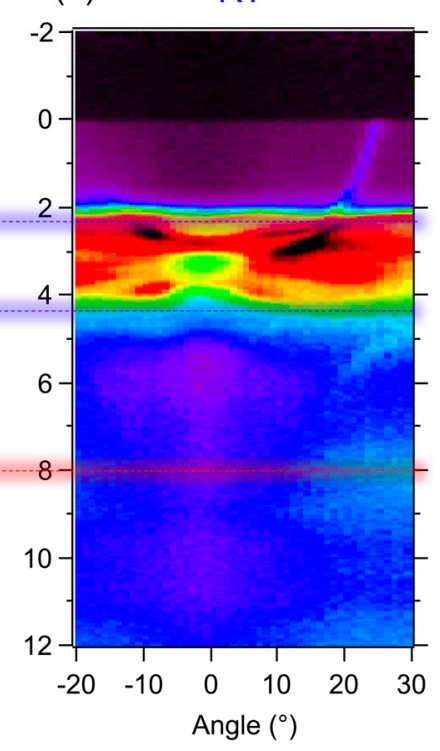

Figure 4. (a) UPS of $\mathrm{BPBr}_{2} / \mathrm{Cu}(111)$ after thermo treatment $\left(\mathrm{RT}, 250^{\circ} \mathrm{C}\right.$ and $515^{\circ} \mathrm{C}$ ) in comparison to the bare $\mathrm{Cu}(111)$ substrate. (b-d) ARUPS map of the corresponding samples. The blue arrows and dashed lines point to features related to the $\mathrm{BPBr}_{2}$ intermediate products as they were not visible on bare $\mathrm{Cu}(111)$, nor on the $515{ }^{\circ} \mathrm{C}$ sample. The red arrow and dashed line point to a new band dispersion after $\mathrm{C}-\mathrm{C}$ bonding $\left(250^{\circ} \mathrm{C}\right)$. This new state stayed and became ever stronger after the de-brominating process $\left(515^{\circ} \mathrm{C}\right)$.

In conclusion, we presented the synthesis and preliminary characterization of a new low-dimensional planar carbon allotrope based on biphenylene via on-surface Ullmann coupling. We traced the whole bottom-up synthesis process by PES. Two main steps were observed, one at $a b .200{ }^{\circ} \mathrm{C}$ for the $\mathrm{C}-\mathrm{C}$ covalent bond formation and another from ab. $400{ }^{\circ} \mathrm{C}$ for the debromination process. After annealing to $515^{\circ} \mathrm{C}$, an ultra-flat and homogenous carbon film was obtained, showing delocalized electronic states. This new low-dimensional planar carbon allotrope provides an important insight towards a new 2D material to the existing carbon networks based on biphenylene. This material has good electronic properties and is thermally stable, constituting a good candidate for electronics of the future.

We note that for the morphology and local electronic property characterization of this new low-dimensional planar carbon material, further investigations are required to complete our spectroscopic results, preferentially by means of AFM/STM techniques. Preliminary STM results are shown in the SI file, suggesting that the cyclobutadiene rings within the biphenylene molecules are likely to participate in the reaction, and the final product is more complicated than just BPC or BPN. We consider the possibility that there is a competition between the Ullmann-type reaction and cyclobutadiene ring opening and recombining, which makes the reaction mechanism even more inspiring and interesting.

Supplementary Materials: The following are available online at https:/ /www.mdpi.com/article/10 .3390 / chemistry3030076/s1, Methods, STM results and synthesis route for $\mathrm{BPBr}_{2}$. Figure S1: STM image of $\mathrm{BPBr}_{2} / \mathrm{Cu}(111)$ system prepared at RT; Figure S2: STM image of $\mathrm{BPBr}_{2} / \mathrm{Cu}(111)$ system after annealing to $200^{\circ} \mathrm{C}$; Figure S3: STM image of $\mathrm{BPBr}_{2} / \mathrm{Cu}(111)$ system after annealing to $500{ }^{\circ} \mathrm{C}$.

Author Contributions: Conceptualization, T.Z., C.G., C.P. and Y.W.; investigation and analysis, T.Z., C.G, H.Y., L.J. and L.L.; theory, I.E.B.; methodology, C.G.; synthesis, K.J. and X.Z.; writing, T.Z. and C.G. All authors have read and agreed to the published version of the manuscript. 
Funding: This research was funded by the National Natural Science Foundation of China (Nos. 61901038, 61971035, 61725107), Beijing Natural Science Foundation (Nos. Z190006, 4192054) and National Key Research and Development Program of China (2020YFA0308800, 2019YFA0308000).

Data Availability Statement: Data available on request from the corresponding author.

Acknowledgments: The authors acknowledge the staff of ANCHOR station at ALOISA beamline at the Elettra Sincrotrone, Italy. T.Z. is grateful for the support from the Beijing Institute of Technology Research Fund Program for Young Scholars.

Conflicts of Interest: The authors declare no conflict of interest.

\section{References}

1. Lüder, J.; Puglia, C.; Ottosson, H.; Eriksson, O.; Sanyal, B.; Brena, B. Many-body effects and excitonic features in 2D biphenylene carbon. J. Chem. Phys. 2016, 144, 024702. [CrossRef]

2. Hudspeth, M.A.; Whitman, B.W.; Barone, V.; Peralta, J.E. Electronic Properties of the Biphenylene Sheet and Its One-Dimensional Derivatives. ACS Nano 2010, 4, 4565-4570. [CrossRef]

3. Ferguson, D.; Searles, D.J.; Hankel, M. Biphenylene and Phagraphene as Lithium Ion Battery Anode Materials. ACS Appl. Mater. Interfaces 2017, 9, 20577-20584. [CrossRef]

4. Brunetto, G.; Autreto, P.A.S.; Machado, L.D.; Santos, B.I.; dos Santos, R.P.B.; Galvão, D.S. Nonzero Gap Two-Dimensional Carbon Allotrope from Porous Graphene. J. Phys. Chem. C 2012, 116, 12810-12813. [CrossRef]

5. De La Pierre, M.; Karamanis, P.; Baima, J.; Orlando, R.; Pouchan, C.; Dovesi, R. Ab Initio Periodic Simulation of the Spectroscopic and Optical Properties of Novel Porous Graphene Phases. J. Phys. Chem. C 2013, 117, 2222-2229. [CrossRef]

6. Baughman, R.H.; Eckhardt, H.; Kertesz, M. Structure-property predictions for new planar forms of carbon: Layered phases containing sp2 and sp atoms. J. Chem. Phys. 1987, 87, 6687-6699. [CrossRef]

7. Denis, P.A.; Iribarne, F. Hydrogen storage in doped biphenylene based sheets. Comput. Theor. Chem. 2015, 1062, 30-35. [CrossRef]

8. Fan, Q.; Yan, L.; Tripp, M.W.; Krejčí, O.; Dimosthenous, S.; Kachel, S.R.; Chen, M.; Foster, A.S.; Koert, U.; Liljeroth, P.; et al. Biphenylene network: A nonbenzenoid carbon allotrope. Science 2021, 372, 852-856. [CrossRef] [PubMed]

9. Tyutyulkov, N.; Dietz, F.; Müllen, K.; Baumgarten, M. Structure and energy spectra of a two-dimensional dielectric carbon allotrope. Chem. Phys. Lett. 1997, 272, 111-114. [CrossRef]

10. Karaush, N.N.; Baryshnikov, G.V.; Minaev, B.F. DFT characterization of a new possible graphene allotrope. Chem. Phys. Lett. 2014, 612, 229-233. [CrossRef]

11. Hussain, T.; Hankel, M.; Searles, D.J. Graphenylene Monolayers Doped with Alkali or Alkaline Earth Metals: Promising Materials for Clean Energy Storage. J. Phys. Chem. C 2017, 121, 14393-14400. [CrossRef]

12. Song, Q.; Wang, B.; Deng, K.; Feng, X.; Wagner, M.; Gale, J.D.; Müllen, K.; Zhi, L. Graphenylene, a unique two-dimensional carbon network with nondelocalized cyclohexatriene units. J. Mater. Chem. C 2013, 1, 38-41. [CrossRef]

13. Costantini, R.; Stredansky, M.; Cvetko, D.; Kladnik, G.; Verdini, A.; Sigalotti, P.; Cilento, F.; Salvador, F.; De Luisa, A.; Benedetti, D.; et al. ANCHOR-SUNDYN: A novel endstation for time resolved spectroscopy at the ALOISA beamline. J. Electron Spectrosc. Relat. Phenom. 2018, 229, 7-12. [CrossRef]

14. Gutzler, R.; Cardenas, L.; Lipton-Duffin, J.; El Garah, M.; Dinca, L.E.; Szakacs, C.E.; Fu, C.; Gallagher, M.; Vondráček, M.; Rybachuk, M.; et al. Ullmann-type coupling of brominated tetrathienoanthracene on copper and silver. Nanoscale 2014, 6, 2660-2668. [CrossRef]

15. Galeotti, G.; Di Giovannantonio, M.; Lipton-Duffin, J.; Ebrahimi, M.; Tebi, S.; Verdini, A.; Floreano, L.; Fagot-Revurat, Y.; Perepichka, D.F.; Rosei, F.; et al. The role of halogens in on-surface Ullmann polymerization. Faraday Discuss. 2017, $204,453-469$. [CrossRef] [PubMed]

16. Galeotti, G.; Di Giovannantonio, M.; Cupo, A.; Xing, S.; Lipton-Duffin, J.; Ebrahimi, M.; Vasseur, G.; Kierren, B.; Fagot-Revurat, Y.; Tristant, D.; et al. An unexpected organometallic intermediate in surface-confined Ullmann coupling. Nanoscale 2019, 11, 7682-7689. [CrossRef] [PubMed]

17. Dahal, A.; Batzill, M. Graphene-nickel interfaces: A review. Nanoscale 2014, 6, 2548. [CrossRef] [PubMed]

18. Totani, R.; Grazioli, C.; Zhang, T.; Bidermane, I.; Luder, J.; de Simone, M.; Coreno, M.; Brena, B.; Lozzi, L.; Puglia, C. Electronic structure investigation of biphenylene films. J. Chem. Phys. 2017, 146, 054705. [CrossRef]

19. Reichert, J.; Schiffrin, A.; Auwärter, W.; Weber-Bargioni, A.; Marschall, M.; Dell'Angela, M.; Cvetko, D.; Bavdek, G.; Cossaro, A.; Morgante, A.; et al. 1-Tyrosine on Ag(111): Universality of the Amino Acid 2D Zwitterionic Bonding Scheme? ACS Nano 2010, 4, 1218-1226. [CrossRef]

20. Cossaro, A.; Puppin, M.; Cvetko, D.; Kladnik, G.; Verdini, A.; Coreno, M.; de Simone, M.; Floreano, L.; Morgante, A. Tailoring SAM-on-SAM Formation. J. Phys. Chem. Lett. 2011, 2, 3124-3129. [CrossRef]

21. Stredansky, M.; Sala, A.; Fontanot, T.; Costantini, R.; Africh, C.; Comelli, G.; Floreano, L.; Morgante, A.; Cossaro, A. On-surface synthesis of a 2D boroxine framework: A route to a novel 2D material? Chem. Commun. 2018, 54, 3971-3973. [CrossRef] [PubMed] 